OPEN ACCESS

Edited by:

Ali Taghipour,

Tarbiat Modares University, Iran

Reviewed by:

Mpumelelo Casper Rikhotso,

University of Venda, South Africa

Dawei Cui,

Zhejiang University School of Medicine, China

*Correspondence: Alireza Khatam

akh.alirezakhatami@gmail.com

Specialty section:

This article was submitted to Infectious Diseases - Surveillance,

Prevention and Treatment,

a section of the journal

Frontiers in Medicine

Received: 14 September 2021 Accepted: 29 October 2021

Published: 13 January 2022

Citation:

Razizadeh MH, Khatami A and Zarei M (2022) Global Status of

Bufavirus, Cosavirus, and Saffold

Virus in Gastroenteritis: A Systematic

Review and Meta-Analysis.

Front. Med. 8:775698.

doi: 10.3389/fmed.2021.775698

\section{Global Status of Bufavirus, Cosavirus, and Saffold Virus in Gastroenteritis: A Systematic Review and Meta-Analysis}

\author{
Mohammad Hossein Razizadeh ${ }^{1}$, Alireza Khatami ${ }^{*}$ and Mohammad Zarei ${ }^{2,3}$ \\ ${ }^{1}$ Faculty of Medicine, Department of Virology, Iran University of Medical Sciences, Tehran, Iran, ${ }^{2}$ Renal Division, Brigham and \\ Women's Hospital, Harvard Medical School, Boston, MA, United States, ${ }^{3}$ John B. Little Center for Radiation Sciences, \\ Harvard T.H. Chan School of Public Health, Boston, MA, United States
}

Background: Bufavirus (BuV), Human Cosavirus (HCoSV), and Saffold (SAFV) virus are three newly discovered viruses and have been suggested as possible causes of gastroenteritis (GE) in some studies. The aim of the present study was to estimate the overall prevalence of viruses and their association with GE.

Methods: A comprehensive systematic search was conducted in Scopus, Web of Science, PubMed, and Google scholar between 2007 and 2021 to find studies on the prevalence of BuV, HCoSV, and SAFV viruses.

Result: Meta-analysis of the 46 included studies showed the low prevalence of BuV (1.\%, 95\% Cl 0.6-1.5\%), HCoSV (0.8\%, 95\% Cl 0.4-1.5\%), and SAFV (1.9\%, 95\% $\mathrm{Cl} 1.1-3.1 \%)$ worldwide. Also, no significant association between these viruses and GE was observed. BuV was isolated from patients with GE in Africa, while SAFV was more common in Europe. BuV1 and BuV2 have the same prevalence between the three identified genotypes of BuV. HCoSV-C was the most prevalent genotype of HCoSV, and SAFV2 was the commonest genotype of SAFV. All of these viruses were more prevalent in children older than 5 years of age.

Conclusion: This was the first meta-analysis on the prevalence and association of BuV, HCoSV, and SAFV with GE. While no significant association was found between infection with these viruses and GE, we suggest more studies, especially with case-control design and from different geographical regions in order to enhance our knowledge of these viruses.

Keywords: Bufavirus, Saffold virus, Cosavirus, gastroenteritis, meta-analysis

\section{INTRODUCTION}

Gastroenteritis (GE) is one of the most common illnesses in both children and adults worldwide. The high importance of GE is due to both high morbidity and mortality and also the financial burdens of the disease. Children, the elderly, and immunocompromised individuals are at higher risk of severe GE (1). Infectious agents, particularly viruses are the main cause of GE worldwide (2). Before the implication of Rotavirus vaccination, Rotavirus was the leading cause of viral GE, while other enteric viruses, such as Noroviruses, Astroviruses, and Human adenoviruses, are now the 
most prevalent viruses causing GE (3). Besides the aforementioned enteric viruses, the list of enteric viruses is continuously growing due to the discovery of emerging viruses $(4,5)$. Since still $40 \%$ of cases of GE are of unknown etiology $(6)$, these newly discovered viruses may likely be involved in causing the GE (7).

The Parvoviridae family consists of small, non-enveloped, icosahedral-shaped viruses, which have a single-stranded DNA genome. Members of this family can infect both vertebrates and invertebrates (8). For about 3 decades, Parvovirus B19 was taught to be the only human pathogen in this family (9). In 2005, Human bocavirus 1 was isolated from the nasopharyngeal swab of children with respiratory symptoms. Since 2009, three other types of the virus, named Human bocavirus 2-4, have been isolated from a stool specimen of children with or without GE (10). In 2012, the metagenomic survey of stool samples of children with acute diarrhea in Burkina Faso resulted in the discovery of a new member of this family, which was named Bufavirus (BuV) (9). Human BuVs belong to the genus Protoparvovirus, and, so far, three genotypes of Human BuV have been identified (11).

The Picornaviridae family contains non-enveloped, icosahedral-shaped viruses with a positive-sense single-stranded RNA genome (12). Unlike the Parvoviridae, viruses in the Picornaviridae family are not able to infect invertebrates (13). This family contains a growing number of viruses, which cause a variety of diseases that can affect different organs of the body. In 2007, a new member of this family was isolated from a child with a fever of an unknown origin in the United States. This virus was later named Saffold virus (SAFV); this name was derived from the lead author of the research, Morris Saffold Jones. Phylogenetic analysis showed that this virus is closely related to theilovirus species in the Cardiovirus genus of this family (14). Since then, eight genotypes of SAFV have been identified (15). The other virus in this family is the Cosavirus (CoSV), which was discovered in 2008 in pediatric patients with acute flaccid paralysis and later found in patients with GE (7). These three novel viruses were isolated from patients with different clinical and epidemiologic patterns (4). They were isolated from patients with GE $(6,16)$ and neurological disorders $(17-19)$. While GE is a threat to global health, the causative agents of many cases still remained unclear (4). Therefore, we conducted this systematic review and meta-analysis to (1) elucidate the possible role of these viruses in development of GE and (2) understand the current epidemiologic pattern of these viruses in different parts of the world.

\section{METHODS}

\section{Search Strategy}

This systematic and meta-analysis review was performed using the recommendations of the PRISMA (Preferred Reporting Items for Systematic Reviews and Meta-Analyses) (20). We comprehensively searched from multiple electronic databases, including Web of Science, PubMed, Google scholar, and Scopus. English-language-related articles published from January 2007 to April 2021 were searched by two investigators independently (AK and MZ) using the following keywords: "Bufavirus" OR
"BuV" OR "novel human picornavirus" OR "Saffold virus" OR "SAFV" OR "HCosV" OR "Human Cosavirus" AND "prevalence" OR "epidemiology" OR "molecular prevalence" AND "acute gastroenteritis" OR "diarrhea" OR "gastroenteritis" $\mathrm{OR}$ "gastrointestinal complications. In addition, the reference list of all relevant articles and narrative reviews were retrieved in full to search for additional eligible studies. All selected studies were imported to the EndNote software versionX8 (Thomson Reuters, California) for criteria analysis.

\section{Inclusion and Exclusion Criteria}

The inclusion criteria for the studies were as follows: (1) All observational studies (case-control, cohort, and cross-sectional studies); (2) Published: 2007 to 2021 for SAFV, between 2012 and 2021 for $\mathrm{BuV}$, and between 2008 and 2021 for HCosV; and (3) Studies reporting the molecular techniques of Bufavirus, Saffoldvirus, and Cosavirus among patients with GE across the world. Papers were excluded from this review if (1) Samples were selected entirely from patients with Bufavirus, Saffold virus, and Cosavirus; (2) Research provides incomplete data; and (3) Review articles, congress abstracts, conference papers, meta-analysis, or systematic reviews, and articles in languages other than English.

\section{Data Extraction}

The data were extracted from 46 selected studies by two researchers separately and independently, including the first author's name, location, year of publication, continent, number of investigated patients, number of isolated viruses, target gene, molecular technique, and genotypes. If necessary, any issue related to the selection of studies was resolved by the first and corresponding authors.

\section{Data Synthesis and Statistical Analysis}

We used a random-effect model to estimate the overall prevalence of the $\mathrm{BuV}, \mathrm{SAFV}$, and $\mathrm{HCosV}$, and results are shown in the forest plot with a 95\% confidence interval. Furthermore, evaluation of the prevalence of the viruses was performed on continental, country, diagnostic method, and age as well as gender subgroups. Also, the prevalence of the viruses and their association with GE were estimated and reported by odds ratio (OR). The Egger's test and $I^{2}$ statistic/Cochran's Q statistic were used to determining publication bias and heterogeneity assessments, respectively, and $p<0.05$ was considered statistically significant. All analyses of the present study were performed with comprehensive meta-analysis (V2.2, Bio stat) software.

\section{RESULTS}

\section{Search Results and Studies Characteristics}

Following the initial search strategy in the aforementioned databases, 3,604 original related articles were identified (PubMed: 755, Scopus: 178, Web of Science: 156, Google scholar: 2,515). A total of 46, observational articles, which included 30 crosssectional (BuV: 6, SAFV: 12, and HCosV: 12), seven case-control (BuV: 1, SAFV: 3, and HCosV: 3), and nine cohort (BuV: 5, 


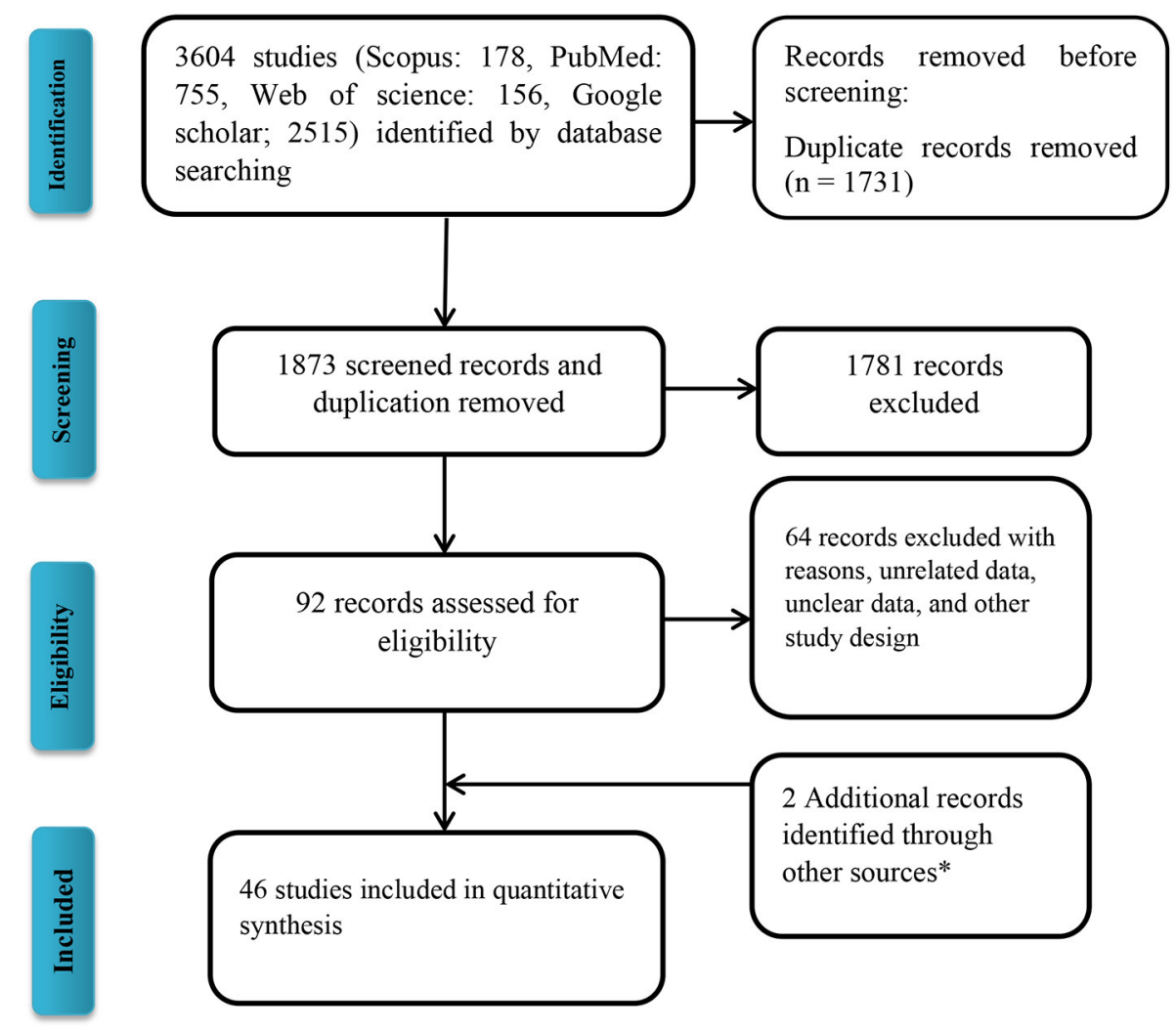

FIGURE 1 | Flow diagram of the literature search for studies included in the meta-analysis. *Including manual search and library records.

SAFV: 3, and HCosV: 1) studies were included based on our inclusion criteria. A summary of the research selection process and the reasons for exclusion is shown in Figure 1. In the case of Bufavirus, five articles were conducted in Europe, four in Asia, and three in Africa. About the Cosavirus, nine in Asia, four in Europe, one in Africa, and two articles were done in America. In the case of Saffold virus, 15 and three were performed in Asia Europe, respectively. Characteristics of the included 46 articles are shown in Tables 1-3.

\section{Pooled Prevalence of Bufavirus in the Patients With Gastroenteritis}

The total number of patients with GE included in this meta-analysis was 7,922 from children and adults based on 11 articles. The pooled prevalence of Bufavirus infection among patients with GE was 1.\% (95\% CI, 0.6-1.5\%) based on a random-effects meta-analysis (Figure 2). In subgroup analysis by continent, the highest prevalence of Bufavirus was seen in Africa (1.4\%, 95\% CI, 0.5-4.1\%) while the lowest prevalence was observed in Asia $(0.7 \%$, 95\% CI, 0.2$2.1 \%$ ) (Table 4). Highest prevalence of virus belongs to older than 5 years old subgroups (3.7\%, 95\% CI: 1.4-9.5\%). As well, in three genotypes of $\mathrm{BuV}, \mathrm{BuV1}$ (1.\%, 95\% CI: $0.3-$ $3.4 \%$ ), and BuV2 (1.\%, 95\% CI: $0.1-6.9 \%)$ were of the same prevalence, while BuV3 (0.7\%, 95\% CI: $0.3-1.7 \%)$ was less prevalent.

\section{The Association of Bufavirus With Gastroenteritis}

In three data sets, the meta-analysis showed that Bufavirus was not associated with GE [OR: 2.191 (95\% CI; 0.384-12.487), $I^{2}$ : 0\%] (Figure 3).

\section{Pooled Prevalence of Saffold Virus in the Patients With Gastroenteritis}

The results of analysis of Saffold virus based on random-effects meta-analysis are summarized in Table 4. Using random-effects meta-analysis, the pooled prevalence of Saffold virus in the studied patients was 1.9\% (95\% CI, 1.1-3.1\%) (Figure 4). Among included studies, the maximum and minimum pooled prevalence of Saffold virus among patients with GE was found in Europe and Asia, respectively (2.9, 95\% CI: $1.2-6.5 \%$ vs. $1.7,95 \%$ CI: $0.9-$ $3.1 \%$ ) (Table 5). The highest prevalence of the virus was detected in children younger than 5 years of old $(2.4 \%, 95 \%$ CI: $0.6-$ 0.9 ). Among the eight genotypes of SAFV, SAFV-2 was the most prevalent genotype (1.\%, 95\% CI: $0.5-1.9 \%)$, and SAFV-4 was the least prevalent $(0.2 \%, 95 \% \mathrm{CI}: 0-1.2 \%)$ in patients with $\mathrm{GE}$.

\section{The Association of Saffold Virus With Gastroenteritis}

Based on the meta-analysis of three case-control studies, there was no significant association between the Saffold virus and GE [OR: 0.768 (95\% CI: 0.437-1.349), $I^{2}$ : 0\%] (Figure 5). 
TABLE 1 | The general characterization of Bufavirus studies

\begin{tabular}{|c|c|c|c|c|c|c|c|c|c|c|c|c|}
\hline References & Study type & Country & Continent & Publishing year & Cases & Positive & Target & Method & $\begin{array}{c}\text { Not } \\
\text { distinguished } \\
\text { Genotype }\end{array}$ & BuV1 & BuV2 & BuV3 \\
\hline Phan et al. (21) & Cross-sectional & Burkina Faso & Africa & 2012 & 98 & 4 & NS1 & Nested RT-PCR & & 3 & 1 & \\
\hline Phan et al. (21) & Cross-sectional & Tunisia & Africa & 2012 & 100 & 0 & NS1 & Nested RT-PCR & & & & \\
\hline Smits et al. (22) & Cross-sectional & Netherlands & Europe & 2014 & 27 & 1 & NS1 & Real-time RT-PCR & & 1 & & \\
\hline Vaisanen et al. (9) & Cross-sectional & Finland & Europe & 2014 & 629 & 7 & VP2 & Real-time RT-PCR & 7 & & & \\
\hline Yahiro et al. (23) & Cross-sectional & Bhutan & Asia & 2014 & 393 & 3 & NS1 & Nested RT-PCR & & & & 3 \\
\hline Huang et al. (16) & Cross-sectional & China & Asia & 2015 & 1877 & 9 & NS1 & Real-time RT-PCR & & 4 & & 5 \\
\hline Altay et al. (24) & Case-control & Turkey & Europe & 2015 & 583 & 8 & & RT-PCR & & & & 8 \\
\hline Chieochansin et al. (25) & Cohort & Thailand & Asia & 2015 & 1414 & 1 & NS1 & Nested RT-PCR & & 1 & & \\
\hline Chieochansin et al. (25) & Cohort & Thailand & Asia & 2015 & 81 & 3 & NS1 & Nested RT-PCR & & 3 & & \\
\hline Ayouni et al. (7) & Cohort & Tunisia & Africa & 2016 & 203 & 2 & NS1 & Nested RT-PCR & & 2 & & \\
\hline Vaisanen et al. (11) & Cohort & Finland & Europe & 2016 & 410 & 3 & NS1 & Real-time RT-PCR & 3 & & & \\
\hline Mohammad et al. (26) & Cross-sectional & Kuwait & Asia & 2020 & 84 & 1 & & Multiplex RT-PCR & & & & 1 \\
\hline Dapra et al. (5) & Cohort & Italy & Europe & 2021 & 160 & 0 & & Real-time RT-PCR & & & & \\
\hline Mohanraj et al. (27) & Cohort & Finland & Europe & 2021 & 243 & 4 & NS1 & $\begin{array}{l}\text { Multiplex real-time } \\
\text { qPCR }\end{array}$ & 4 & & & \\
\hline Mohanraj et al. (27) & Cohort & Finland & Europe & 2021 & 386 & 3 & NS1 & $\begin{array}{l}\text { Multiplex real-time } \\
\text { qPCR }\end{array}$ & 3 & & & \\
\hline Mohanraj et al. (27) & Cohort & Finland & Europe & 2021 & 955 & 3 & NS1 & $\begin{array}{l}\text { Multiplex real-time } \\
\text { qPCR }\end{array}$ & 3 & & & \\
\hline Mohanraj et al. (27) & Cohort & Latvia & Europe & 2021 & 115 & 0 & NS1 & $\begin{array}{l}\text { Multiplex real-time } \\
\text { QPCR }\end{array}$ & 0 & & & \\
\hline Mohanraj et al. (27) & Cohort & Malawi & Africa & 2021 & 164 & 1 & NS1 & $\begin{array}{l}\text { Multiplex real-time } \\
\text { GPCR }\end{array}$ & 1 & & & \\
\hline
\end{tabular}


TABLE 2 | The general characterization of Saffold virus studies.

\begin{tabular}{|c|c|c|c|c|c|c|c|c|c|c|c|c|c|}
\hline References & Study & Country & Continent & Publishing year & Cases & Positive & Target & Method & SAFV-1 & SAFV-2 & SAFV-3 & SAFV-4 & SAFV-6 \\
\hline Ren et al. (28) & Cross-sectional & China & Asia & 2009 & 373 & 12 & $5^{\prime}$ UTR & Nested RT-PCR & 12 & & & & \\
\hline Khamrin et al. (29) & Cross-sectional & Thailand & Asia & 2011 & 150 & 4 & $5^{\prime}$ UTR & Nested RT-PCR & & 4 & & & \\
\hline Dai et al. (30) & Case-control & China & Asia & 2011 & 577 & 6 & $5^{\prime}$ UTR & Nested RT-PCR & & & 3 & & \\
\hline Zhang et al. (31) & Cohort & China & Asia & 2012 & 2,013 & 12 & $5^{\prime}$ UTR & Real-time RT-PCR & & 4 & 5 & & \\
\hline Khamrin et al. (32) & Cross-sectional & Japan & Asia & 2013 & 454 & 7 & $5^{\prime}$ UTR & Nested RT-PCR & & 5 & 2 & & \\
\hline Nielsen et al. (33) & Cohort & Denmark & Europe & 2013 & 386 & 10 & VP1 & Real-time RT-PCR & & 10 & & & \\
\hline Yodmeeklin et al. (34) & Cross-sectional & Thailand & Asia & 2015 & 608 & 9 & $5^{\prime}$ UTR & Nested RT-PCR & 1 & 5 & 2 & 1 & \\
\hline Thongprachum et al. (35) & Cross-sectional & Japan & Asia & 2017 & 751 & 4 & $5^{\prime}$ UTR & Multiplex RT-PCR & & & & & \\
\hline Kumthip et al. (36) & Cross-sectional & Thailand & Asia & 2017 & 73 & 1 & $5^{\prime}$ UTR & Nested RT-PCR & & & & & \\
\hline Menage et al. (6) & Cross-sectional & Thailand & Asia & 2017 & 1,093 & 18 & $5^{\prime}$ UTR & Nested RT-PCR & 3 & 9 & & & 6 \\
\hline Li et al. (37) & Case-control & China & Asia & 2017 & 461 & 7 & VP1 & Nested RT-PCR & 3 & 4 & & & \\
\hline Dapra et al. (38) & Cross-sectional & Italy & Europe & 2018 & 164 & 1 & & $N R^{*}$ & & & & & \\
\hline Malasao et al. (39) & Cross-sectional & Thailand & Asia & 2019 & 2,002 & 30 & & NR & & & & & \\
\hline Kim et al. (40) & Cross-sectional & South Korea & Asia & 2020 & 801 & 0 & & Multiplex RT-PCR & & & & & \\
\hline Mohammad et al. (26) & Cross-sectional & Kuwait & Asia & 2020 & 84 & 1 & & Metagenomics sequencing & & & & & \\
\hline Vandesande et al. (41) & Cohort & Sweden & Europe & 2021 & 209 & 11 & 5' UTR & Semi-nested RT-PCR & & & 1 & & \\
\hline Yaghobi et al. (42) & Cross-sectional & Iran & Asia & 2020 & 160 & 26 & $5^{\prime}$ UTR & RT-PCR & & & & & \\
\hline Taghinejad et al. (43) & Cross-sectional & Iran & Asia & 2020 & 160 & 11 & & RT-PCR & & & & & \\
\hline
\end{tabular}

${ }^{*} N R$, Not reported. 
TABLE 3 | The general characterization of Cosavirus studies.

\begin{tabular}{|c|c|c|c|c|c|c|}
\hline References & Study & Publishing year & Country & Continent & Cases & Positive \\
\hline Nielsen et al. (33) & Cohort & 2013 & Denmark & Europe & 386 & 0 \\
\hline Stocker et al. (44) & Case-control & 2012 & Brazil & America & 359 & 13 \\
\hline Vizzi et al. (45) & Case-control & 2021 & Venezuela & America & 82 & 5 \\
\hline Yu et al. (46) & Case-control & 2017 & China & Asia & 461 & 8 \\
\hline Ayouni et al. (7) & Cross-sectional & 2016 & Tunisia & Africa & 203 & 2 \\
\hline Dapra et al. (38) & Cross-sectional & 2018 & Italy & Europe & 164 & 0 \\
\hline Dapra et al. (5) & Cross-sectional & 2021 & Italy & Europe & 160 & 0 \\
\hline Khamrin et al. (47) & Cross-sectional & 2012 & Thailand & Asia & 300 & 1 \\
\hline Khamrin et al. (48) & Cross-sectional & 2014 & Thailand & Asia & 411 & 1 \\
\hline Kim et al. (40) & Cross-sectional & 2020 & South Korea & Asia & 801 & 0 \\
\hline Menage et al. (6) & Cross-sectional & 2017 & Thailand & Asia & 1,093 & 16 \\
\hline Mohammad et al. (26) & Cross-sectional & 2020 & Kuwait & Asia & 84 & 1 \\
\hline Okitsu et al. (49) & Cross-sectional & 2014 & Japan & Asia & 630 & 1 \\
\hline Rovida et al. (50) & Cross-sectional & 2013 & Italy & Europe & 689 & 1 \\
\hline Thongprachum et al. (35) & Cross-sectional & 2017 & Japan & Asia & 751 & 1 \\
\hline Kochjan et al. (51) & Cross-sectional & 2016 & Thailand & Asia & 21 & 1 \\
\hline
\end{tabular}

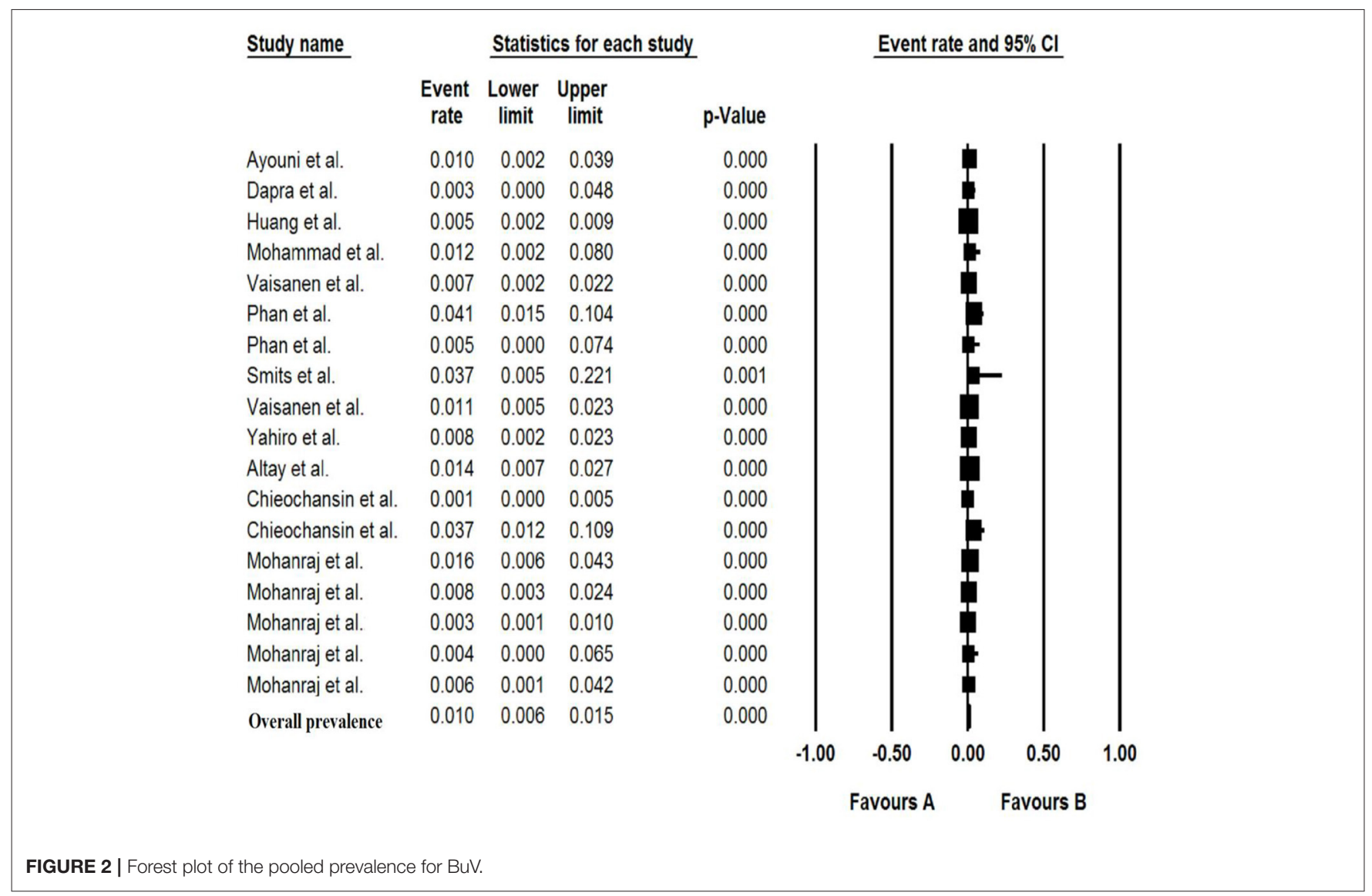

Pooled Prevalence of Human Cosavirus in the Patients With Gastroenteritis

The total number of patients with GE included in this meta-analysis was 6,595 based on 16 included articles. Based on a random-effect meta-analysis, the pooled prevalence of the human Cosavirus infection among patients with GEs was $0.8 \%$ (95\% CI, 0.4-1.5\%) (Figure 6). In subgroup analysis by continent, the highest prevalence of Cosavirus was 
TABLE 4 | The Bufavirus prevalence based on subgroups and studies heterogeneity.

\begin{tabular}{|c|c|c|c|c|c|c|}
\hline \multirow[t]{2}{*}{ Characteristics } & \multirow[t]{2}{*}{ Categories } & \multirow[t]{2}{*}{ Data sets } & \multirow{2}{*}{$\begin{array}{l}\text { Pooled prevalence (\%) } \\
\qquad(95 \% \mathrm{Cl})\end{array}$} & \multicolumn{3}{|c|}{ Heterogeneity } \\
\hline & & & & $Q$ value & $P$-value & $I^{2 \%}$ \\
\hline Overall & - & 18 & $1.0(0.6-1.5)$ & 35.005 & 0.006 & 51.435 \\
\hline \multirow[t]{3}{*}{ Continent } & Africa & 4 & $1.4(0.5-4.1)$ & 5.486 & 0.139 & 45.319 \\
\hline & Asia & 5 & $0.7(0.2-2.1)$ & 15.201 & 0.004 & 73.685 \\
\hline & Europe & 9 & $1.0(0.7-1.4)$ & 9.203 & 0.325 & 13.071 \\
\hline \multirow[t]{3}{*}{ Method } & Nested RT-PCR & 5 & $1.1(0.4-3.1)$ & 18.311 & 0.003 & 72.694 \\
\hline & Real-time RT-PCR & 5 & $0.8(0.4-1.4)$ & 5.853 & 0.210 & 31.660 \\
\hline & multiplex real-time qPCR & 5 & $0.7(0.4-1.4)$ & 4.975 & 0.290 & 19.599 \\
\hline \multirow[t]{3}{*}{ Genotype } & BuV1 & 6 & $1.0(0.3-3.4)$ & 27.351 & 0.000 & 81.719 \\
\hline & BuV2 & 1 & $1.0(0.1-6.9)$ & 0.000 & 1.000 & 0.000 \\
\hline & BuV3 & 4 & $0.7(0.3-1.7)$ & 8.548 & 0.036 & 0.501 \\
\hline \multirow[t]{4}{*}{ Co-infection } & NoV & 6 & $0.3(0.1-0.5)$ & 4.103 & 0.535 & 0.000 \\
\hline & HBoV & 2 & $0.3(0.1-0.9)$ & 0.078 & 0.780 & 0.000 \\
\hline & RoV & 2 & $0.6(0.2-2.2)$ & 1.307 & 0.253 & 23.480 \\
\hline & $A d V$ & 1 & $1.0(0.2-3.9)$ & 0.000 & 1000 & 0.000 \\
\hline \multirow[t]{2}{*}{ Age } & Under 5 & 5 & $1.4(0.6-2.9)$ & 7.381 & 0.117 & 45.804 \\
\hline & Over 5 & 2 & $3.7(1.4-9.5)$ & 0.000 & 1.000 & 0.000 \\
\hline \multirow[t]{2}{*}{ Sex } & Male & 4 & $0.9(0.2-4.4)$ & 12.447 & 0.006 & 75.898 \\
\hline & Female & 4 & $0.6(0.2-1.8)$ & 4.279 & 0.233 & 29.883 \\
\hline
\end{tabular}

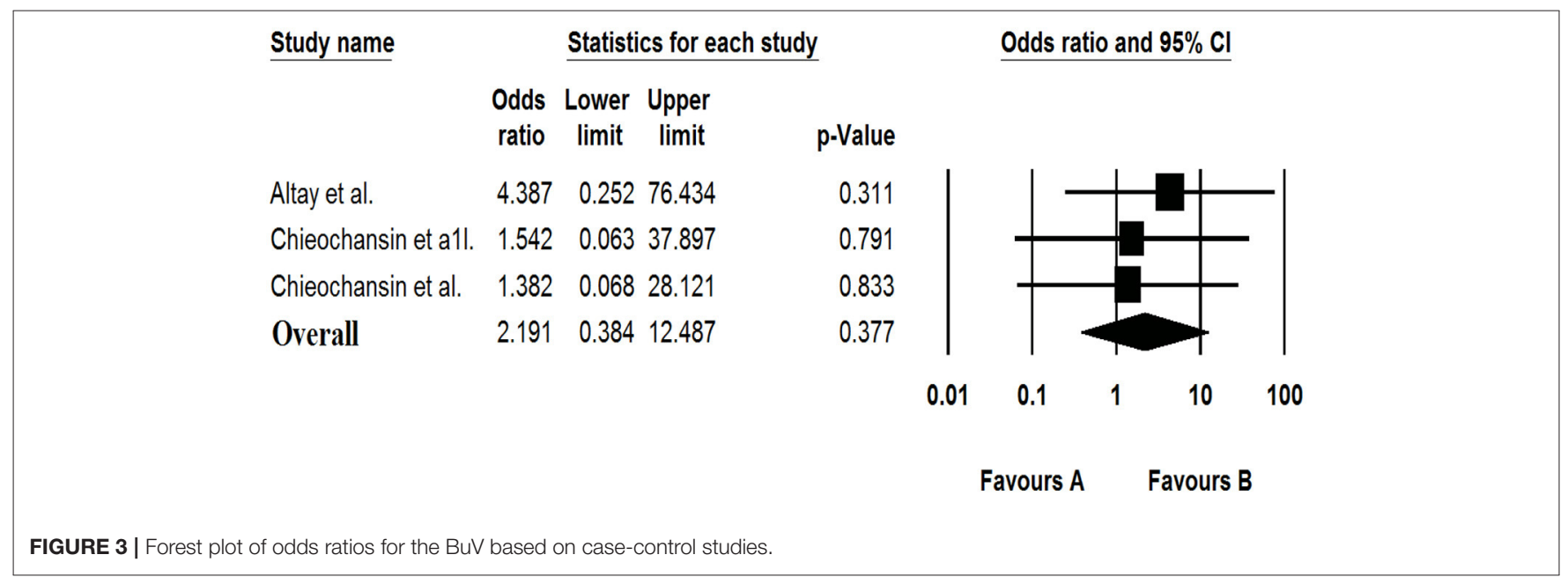

seen in America $(4.2 \%, 95 \% \mathrm{CI}, 2.6-6.6 \%)$, whereas Europe $(0.2 \%, 95 \% \mathrm{CI}, 0.1-0.7 \%)$ observed the lowest prevalence (Table 6).

\section{The Association of Human Cosavirus With Gastroenteritis}

Of the four included case-control studies, one study could not be analyzed due to zero values for cases and controls (33), and, according to the three analyzed studies, human Cosavirus was not associated with GE [OR: 0.730 (95\% CI; 0.054-9.886), $I^{2}: 0 \%$ ] (Figures 3, 7).

\section{Publication Bias and Heterogeneity Assessment}

The publication bias results were not significant for two viruses (SAFV and $\mathrm{BuV}$ ) and significant for Cosavirus prevalence reports by applying Egger's regression test $(P=0.1912$ for SAFV, $P=0.5667$ for $\mathrm{BuV}$, vs. $P=0.0031$ for Cosavirus) (as shown in Figure 8). Also, the heterogeneity results of the studies according to the $I^{2}$ statistics and Cochran's Q statistics were statistically significant for $\mathrm{BuV}(Q=35.005$, $\left.p<0.006, I^{2}=51.435 \%\right)$, SAFV $(Q=174.465, p<0$, $\left.I^{2}=90.256 \%\right)$, and Cosavirus $\left(Q=28.29, P=0, I^{2}=92.932\right)$ (Tables 4-6). 


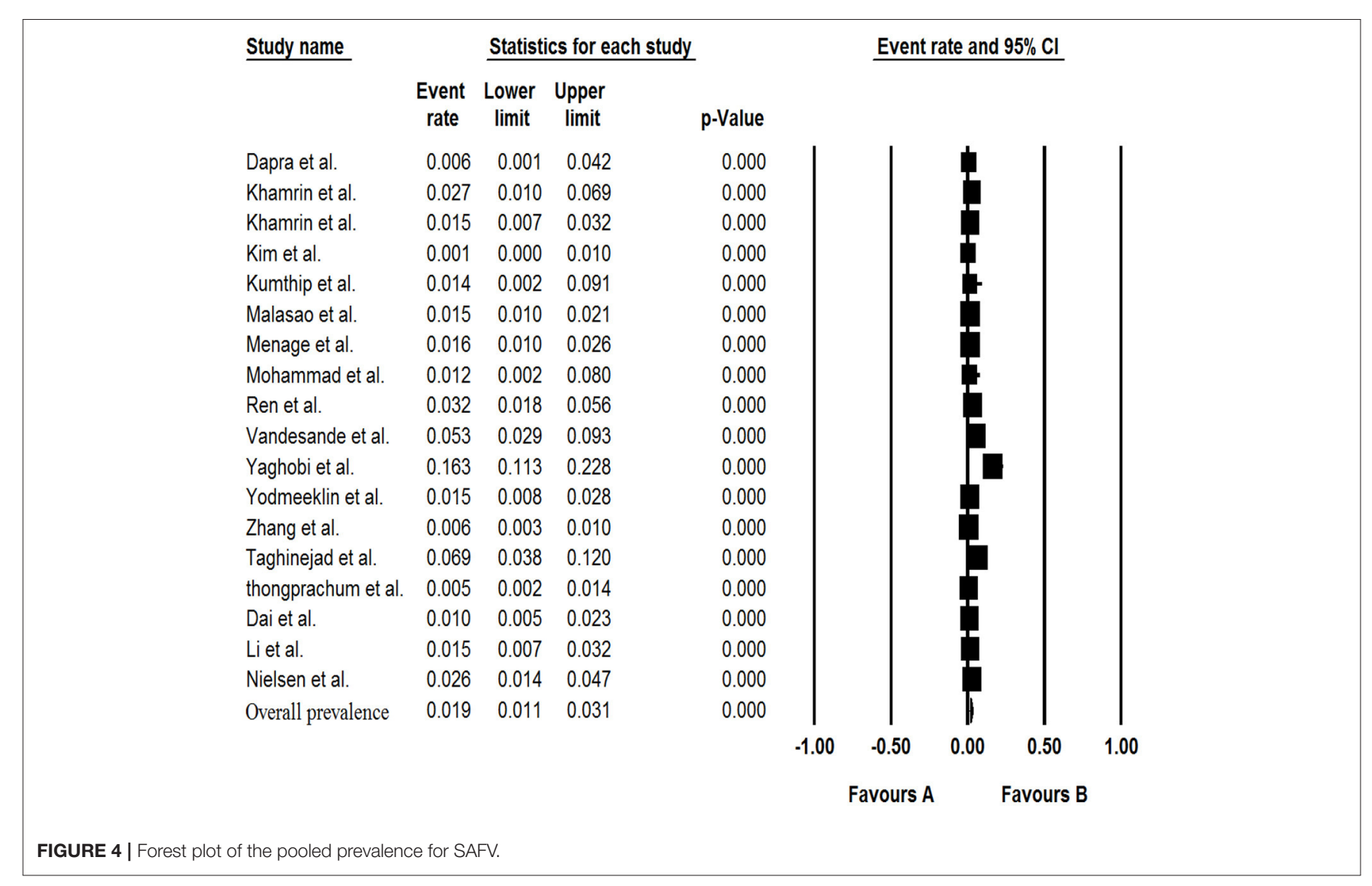

\section{DISCUSSION}

Rapid progressions in sequencing technologies, bioinformatics, and metagenomic have led to the discovery of new viruses in recent years. However, while some studies stated the isolation of new viruses from fecal samples of patients with GE, there is still no solid evidence of the association of these viruses with GE $(4,52,53)$. They are often neglected in epidemiological studies as they cause milder or asymptomatic infection, and researchers have a higher tendency to detect common enteric viruses and other infectious agents in patients with GE (5456). In the present meta-analysis, we investigated the role of three emerging discovered viruses in the development of GE. Our results show no association between infection with Bufavirus (OR; 2.91, 95\% CI: 0.384-12.487), Cosavirus (OR; 0.73, 95\% CI: 0.054-9.886), and Saffold virus (OR; 0.77, 95\% CI: 0.44-1.35) with GE. Also, a low prevalence of $\mathrm{BuV}$ (1.\%, 95\% CI: 0.6$1.5 \%), \operatorname{HCoSV}(0.8 \%, 95 \% \mathrm{CI}: 0.4-1.5 \%)$, and SAFV (1.9\%, 95\% CI: $1.1-3.1 \%)$ was observed. In general, the prevalence of SAFV was higher than $\mathrm{BuV}$, and the least prevalence was observed in the case of $\mathrm{HCoSV}$. The highest prevalence of $\mathrm{BuV}$ was in Africa (1.4\%, 95\% CI: 0.5-4.1\%), where it was discovered (21), and the least prevalence was in Asia (0.7\%, 95\% CI: $0.2-2.1 \%)$. This might be due to poor hygiene and lack of access to safe water in African countries. Given the fact that these viruses were detected in environmental and sewage samples from various parts of the world (57-62), they possibly transmit through the oral-fecal route.

About the three genotypes of $\mathrm{BuV}, \mathrm{BuV} 1$, and $\mathrm{BuV} 2$ were of the same prevalence, while $\mathrm{BuV} 3$ was less common in patients with GE; this lower prevalence of $\mathrm{BuV} 3$ might be due to the later discovery of this genotype in 2014 (23). SAFV consists of eight genotypes, of which five (SAFV1-4 and 6) were found in the included studies. SAFV-2 was the most prevalent genotype, and SAFV-4 was the least prevalent in patients with GE. It should be pointed out that, although SAFV genotypes 5,7 , and 8 were not detected in the included studies, Blinkova et al. isolated them along with other genotypes in children with non-polio acute flaccid paralysis (63). Also, some of the included studies did not investigate the genotypes of isolated SAFVs. Therefore, we cannot conclude that they are not present in fecal samples of patients with GE. The genotype A of $\mathrm{HCoSV}$ was more frequently $(0.5 \%, 95 \%$ CI: $0.1-2.1 \%)$ isolated from patients with GE. Other founded genotypes were Genotype D (0.2\%, 95\% CI: $0-0.7 \%)$ and C (0.1\%, 95\% CI: 0-0.6\%).

The presence of common enteric viruses, such as Rotavirus (RoV), human bocavirus (HBoV), Adenovirus (AdV), and Norovirus $(\mathrm{NoV})$, was observed in patients that are $\mathrm{BuV}$ and SAFV infected. According to the Tables 4-6, co-infection with NoV was more common in patients infected with SAFV than $\mathrm{BuV}$. There was a similar situation in the case of $\mathrm{HBoV}$ in which more prevalence of this virus was seen in SAFV than patients 
TABLE 5 | The Saffold virus prevalence based on subgroups and studies heterogeneity.

\begin{tabular}{|c|c|c|c|c|c|c|}
\hline \multirow[t]{2}{*}{ Characteristics } & \multirow[t]{2}{*}{ Categories } & \multirow{2}{*}{$\begin{array}{l}\text { No. of } \\
\text { Datasets }\end{array}$} & \multirow{2}{*}{$\begin{array}{l}\text { Pooled prevalence (\%) } \\
\qquad(95 \% \mathrm{Cl})\end{array}$} & \multicolumn{3}{|c|}{ Heterogeneity } \\
\hline & & & & $Q$ value & $P$-value & $I^{2} \%$ \\
\hline Overall & - & 18 & $1.9(1.1-3.1)$ & 174.465 & 0.000 & 90.256 \\
\hline \multirow[t]{2}{*}{ Continent } & Asia & 15 & $1.7(0.9-3.1)$ & 165.693 & 0.000 & 91.553 \\
\hline & Europe & 3 & $2.9(1.2-6.5)$ & 5.965 & 0.051 & 66.471 \\
\hline \multirow[t]{5}{*}{ Genotype } & SAFV-1 & 5 & $0.9(0.3-2.6)$ & 25.159 & 0.000 & 84.101 \\
\hline & SAFV-2 & 7 & $1.0(0.5-1.9)$ & 23.800 & 0.001 & 74.790 \\
\hline & SAFV-3 & 6 & $0.6(0.2-1.5)$ & 23.853 & 0.000 & 79.038 \\
\hline & SAFV-4 & 1 & $0.2(0.0-1.2)$ & 0.000 & 1.000 & 0.000 \\
\hline & SAFV-6 & 1 & $0.5(0.2-1.2)$ & 0.000 & 1.000 & 0.000 \\
\hline \multirow[t]{4}{*}{ Co-infection } & NoV & 6 & $0.6(0.3-1.0)$ & 8.635 & 0.125 & 42.097 \\
\hline & $\mathrm{HBoV}$ & 2 & $0.4(0.1-1.5)$ & 1.457 & 0.227 & 31.352 \\
\hline & RoV & 8 & $0.4(0.2-0.9)$ & 19.395 & 0.007 & 63.909 \\
\hline & $\mathrm{AdV}$ & 4 & $0.2(0.1-0.5)$ & 2.624 & 0.453 & 0.000 \\
\hline \multirow[t]{3}{*}{ Method } & Multiplex RT-PCR & 2 & $0.3(0.0-1.9)$ & 2.052 & 0.152 & 51.263 \\
\hline & Nested RT-PCR & 7 & $2.3(1.5-3.5)$ & 14.417 & 0.025 & 58.383 \\
\hline & RT-PCR & 2 & 10.9 (4.6-24.) & 6.505 & 0.011 & 84.627 \\
\hline \multirow[t]{2}{*}{ Age } & Under 5 & 8 & $1.6(0.5-4.5)$ & 70.138 & 0.000 & 90.020 \\
\hline & Over 5 & 3 & $2.4(0.6-0.9)$ & 4.183 & 0.124 & 52.184 \\
\hline \multirow[t]{2}{*}{ Sex } & Male & 2 & $0.3(0.0-2.2)$ & 0.984 & 0.321 & 0.000 \\
\hline & Female & 2 & $0.9(0.0-19.7)$ & 3.846 & 0.050 & 73.999 \\
\hline
\end{tabular}

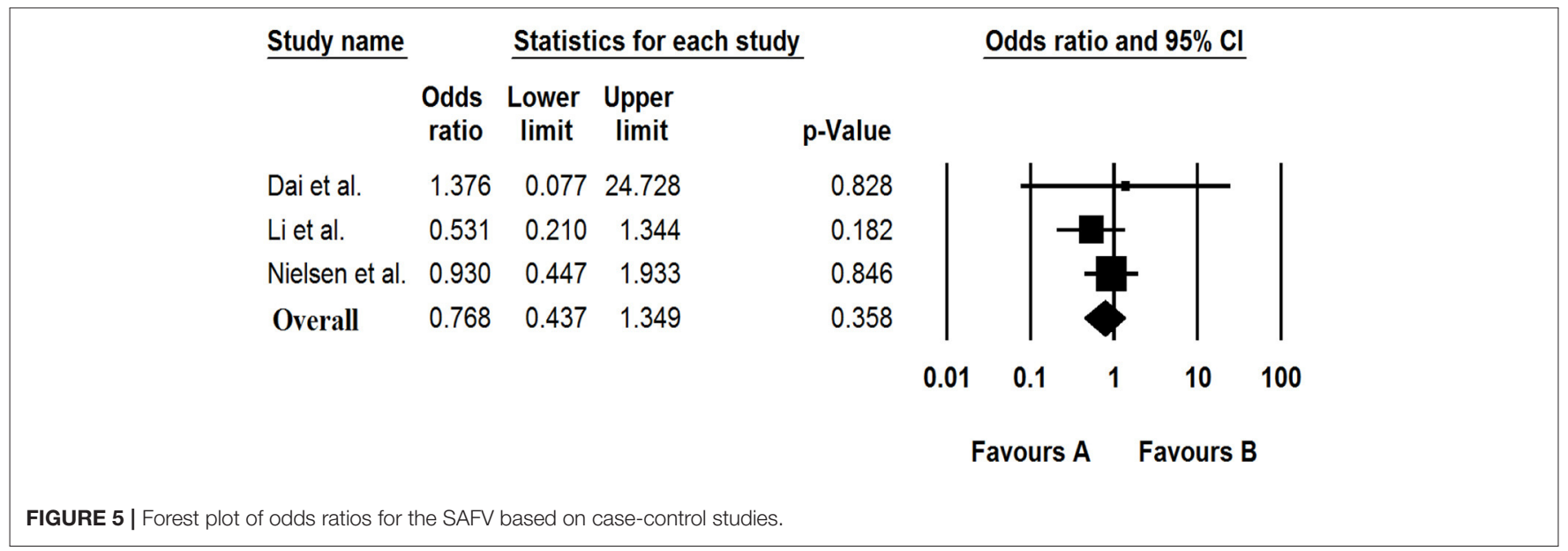

who are $\mathrm{BuV}$ infected. Contrastingly, RoV infection was more frequent in patients infected with $\mathrm{BuV}$ than SAFV. Similarly, $\mathrm{AdV}$ infection was more common in patients with $\mathrm{BuV}$ than SAFV infection. EVs have the highest proportion of co-infection with HCoSV followed by AdVs, RoVs, and NoVs. The high rate of co-infection with classic enteric viruses may indicate the role of these viruses in causing symptoms in patients infected with these newly discovered viruses $(6,46)$. The other possible point that is against the pathologic role of these viruses in the development of GE is the low viral load in patients with GE, which might be due to transient infection and the lack of replication in the gastrointestinal tract (44). Also, the high presence of these viruses in healthy individuals raises the likelihood that they are a part of the human virome (6).

Three studied viruses can infect people of all age groups $(16,41)$. Our analysis showed that $\mathrm{BuV}$ and SAFV are more common in individuals older than 5 years of age. In contrast, $\mathrm{HCoSV}$ was more common in the children younger than 15 years old. While GE is known as a prevalent disease in children younger than 5 years of age and common enteric viruses such as RoV and $\mathrm{NoV}$ are mostly found in this age group $(64,65)$, interestingly, our analysis showed that these viruses are more prevalent in older patients. These results might be due to reason that outdoor activities further expose people to viral agents (52). 
TABLE 6 | The Cosavirus prevalence based on subgroups and studies heterogeneity.

\begin{tabular}{|c|c|c|c|c|c|c|}
\hline \multirow[t]{2}{*}{ Characteristics } & \multirow[t]{2}{*}{ Categories } & \multirow{2}{*}{$\begin{array}{l}\text { No. of } \\
\text { Data } \\
\text { sets }\end{array}$} & \multirow{2}{*}{$\begin{array}{l}\text { Pooled prevalence }(\%) \\
(95 \% \mathrm{Cl})\end{array}$} & \multicolumn{3}{|c|}{ Heterogeneity } \\
\hline & & & & $Q$ value & $P$-value & $I^{2} \%$ \\
\hline Overall & - & 16 & $0.8(0.4-1.5)$ & 28.29 & 0.000 & 92.932 \\
\hline \multirow[t]{3}{*}{ WHO regions } & Africa & 1 & $1.0(0.2-3.9)$ & 0.000 & 1.000 & 0.000 \\
\hline & America & 2 & $4.2(2.6-6.6)$ & 1.022 & 0.312 & 2.185 \\
\hline & Asia & 9 & $0.7(0.3-1.4)$ & 21.240 & 0.007 & 62.335 \\
\hline \multirow{2}{*}{ Genotype } & HCoSV-C & 1 & $0.1(0.0-0.6)$ & 0.000 & 1.000 & 0.000 \\
\hline & HCoSV-D & 2 & $0.2(0.0-0.7)$ & 0.837 & 0.360 & 0.000 \\
\hline \multirow[t]{3}{*}{ Co-infection } & NoV & 2 & $0.2(0.0-1.1)$ & 1.420 & 0.233 & 29.561 \\
\hline & EV & 3 & $0.7(0.1-3.3)$ & 5.932 & 0.052 & 66.286 \\
\hline & RoV & 3 & $0.4(0.2-0.8)$ & 1.384 & 0.500 & 0.000 \\
\hline Age & $>15$ & 2 & $0.4(0.1-1.8)$ & 0.319 & 0.517 & 0.000 \\
\hline
\end{tabular}

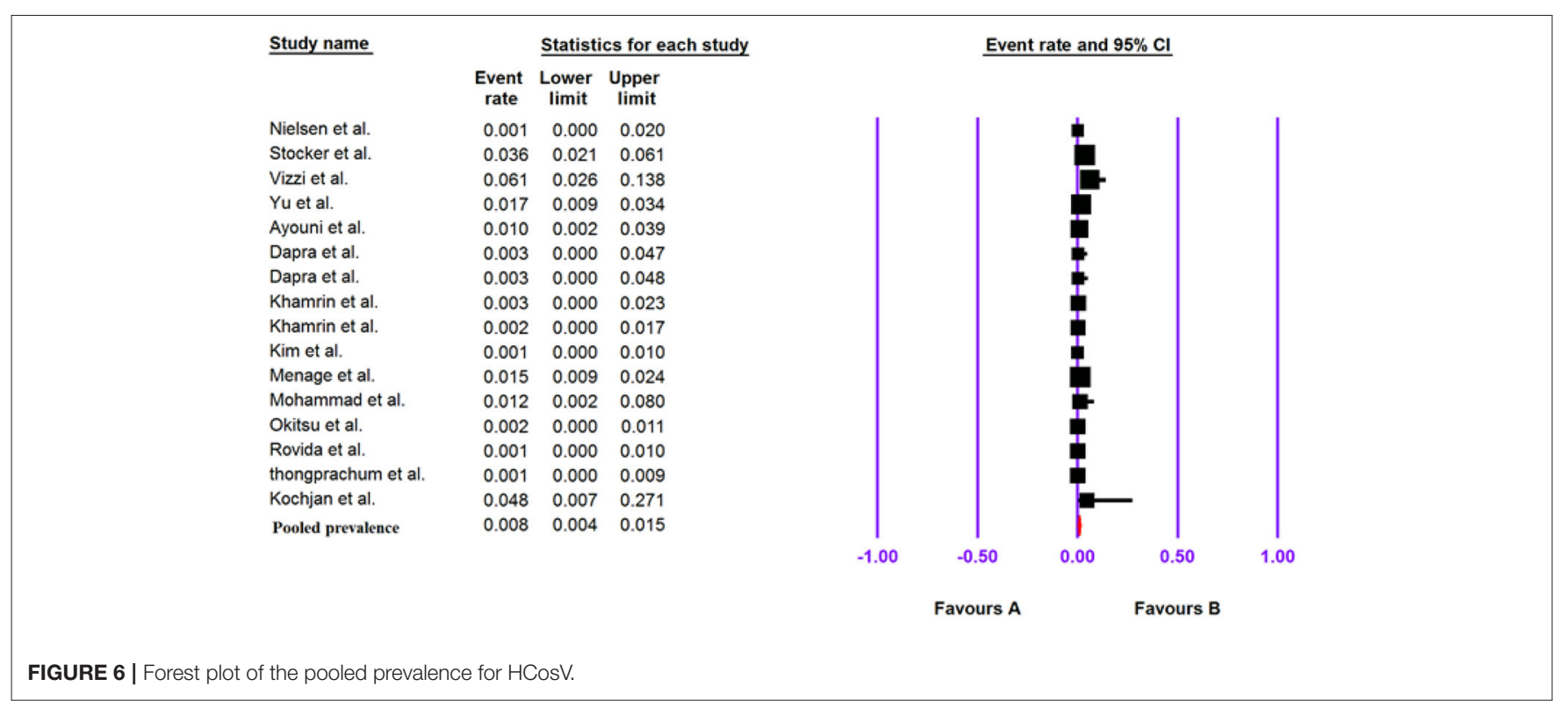

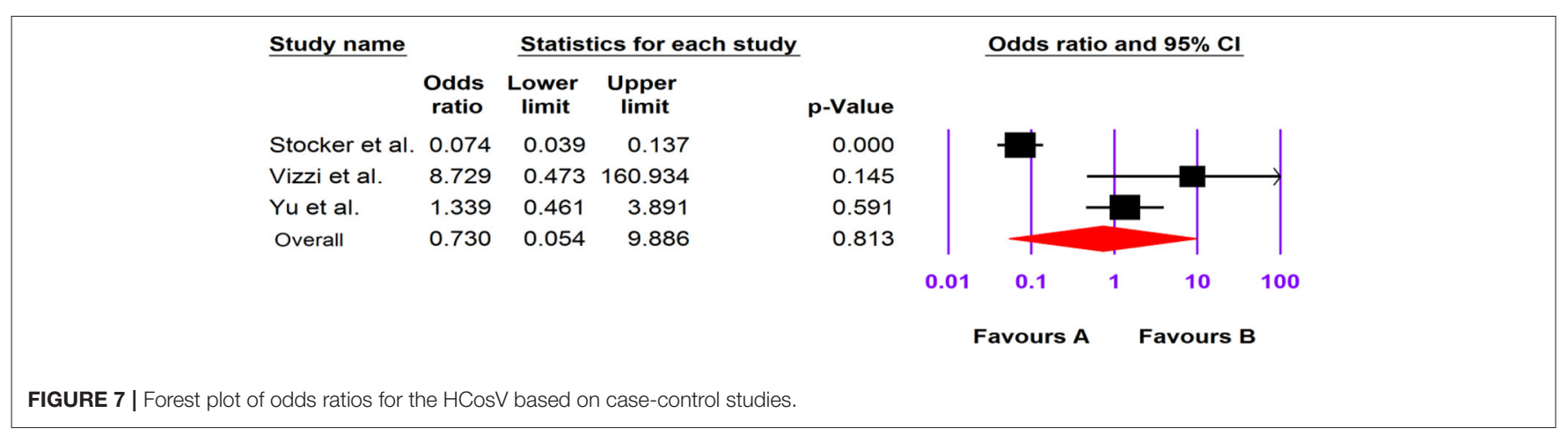




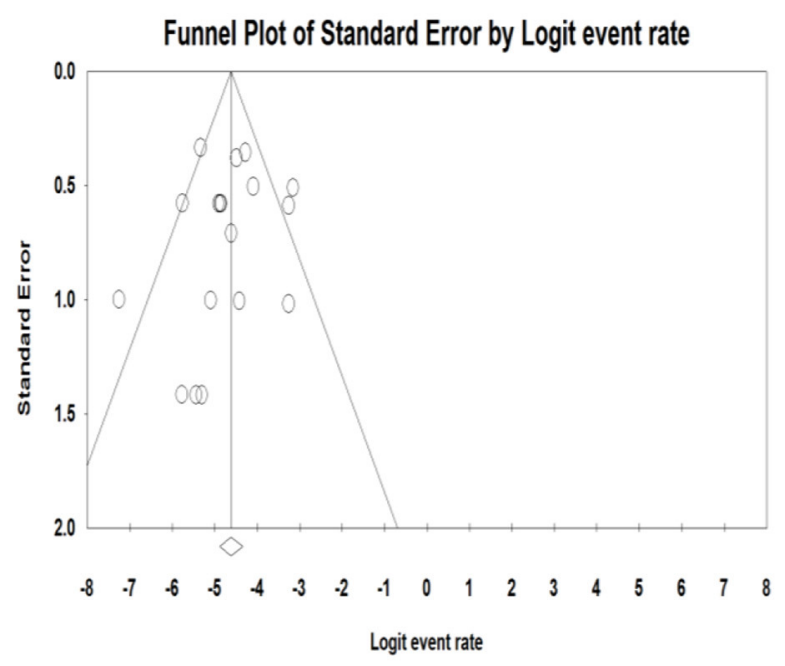

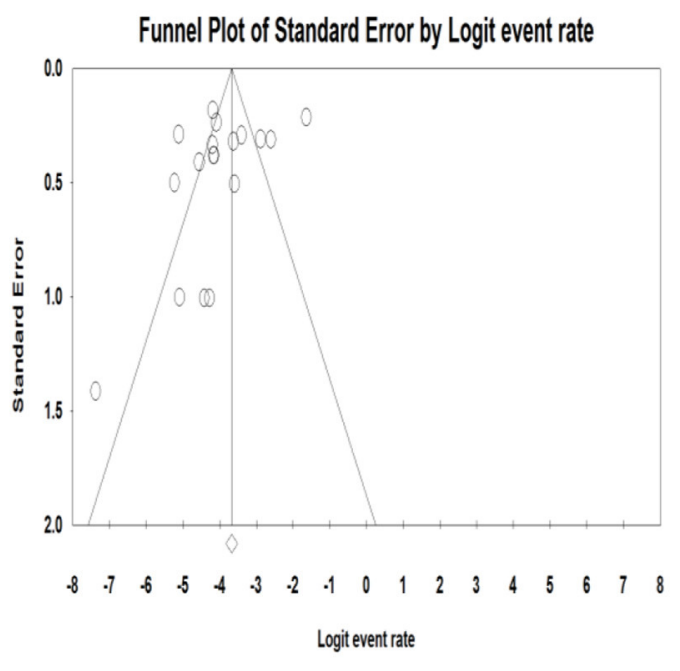

C

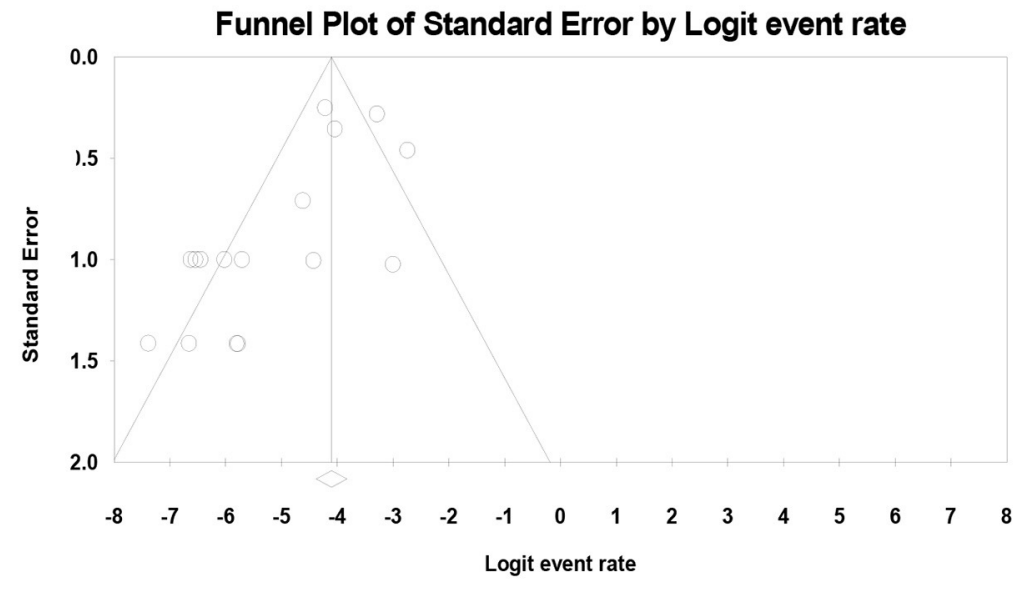

FIGURE 8 | Funnel plot for publication bias assessment in BuV (A), SAFV (B), and CosV (C).

$\mathrm{BuV}$ and SAFV are differently distributed among males and females, while $\mathrm{BuV}$ is more prevalent in males than females; SAFV is more common in females (42). However, these slight differences do not implicate that these viruses have a higher tendency to infect people of a specific gender.

All included studies had a molecularly based diagnosis with relatively close sensitivity and specificity. However, in the case of SAFV, RT-PCR had the highest detection, while nested-PCR showed the highest detection rate for $\mathrm{BuV}$. It is noteworthy to mention that it requires more studies on the sensitivity and specificity of these methods to conclude which one is more suitable.

The present study faced some limitations. There were a few studies on adults, and details of participants (gender, clinical signs, and age groups) were insufficient in some studies. The genotypes of the viruses were not reported from some studies, and also some of research conducted without a healthy control group. The prevalence of these viruses had not been reported in many countries and geographical areas. In addition, some of the included studies did not evaluate the co-infection of the novel viruses with common enteric viruses. In addition, the language limitations of many studies and lack of association assessments of genotypes and clinical signs were the other main limitations of the present study. Hence, we suggest further studies, especially in case-control design, and more comprehensive studies from different geographical areas to overcome these limitations.

\section{CONCLUSION}

Progression in the development of molecular and metagenomics methods has facilitated discovering and studying emerging 
viruses. In the present meta-analysis, we investigated the prevalence and role of three recently discovered viruses in the development of GE. The pooled prevalence of three viruses was low, and neither was associated with GE. These results might be due to the few numbers of studies conducted. Therefore, we suggest more comprehensive studies with large cohorts of symptomatic and healthy patients in order to enhance our knowledge about these newly identified viruses. Also, we recommend in vitro studies to investigate the possible effects of these viruses on the gastrointestinal cell lines. In addition, the possible role of these emerging viruses in the etiology of other complications, such as respiratory symptoms, neurological diseases, and fever of an unknown origin, should not be neglected.

\section{REFERENCES}

1. Eckardt AJ, Baumgart DC. Viral gastroenteritis in adults. Recent Patents Anti Infect Drug Discov. (2011) 6:54-63. doi: 10.2174/157489111794 407877

2. Kesheh MM, Khatami A, Saadati H, Jabbari M, Razizadeh MH, Fatemipour $\mathrm{M}$, et al. Salivirus Infection: Systematic Review and Meta-Analysis of Association With Gastrointestinal Symptoms in Children. New York, NY: Wiley Online Library.

3. Arashkia A, Bahrami F, Farsi M, Nejati B, Jalilvand S, Nateghian A, et al. Molecular analysis of human adenoviruses in hospitalized children $<5$ years old with acute gastroenteritis in Tehran, Iran. J Med Virol. (2019) 91:19306. doi: 10.1002/jmv.25539

4. Smits SL, Osterhaus AD, Koopmans MP. Newly identified viruses in human gastroenteritis: pathogens or not? Pediatr Infect Dis J. (2016) 35:1047. doi: 10.1097/INF.0000000000000950

5. Daprà V, Galliano I, Montanari P, Zaniol E, Calvi C, Alliaudi C, et al. Bufavirus, Cosavirus, and Salivirus in diarrheal Italian infants. Intervirology. (2021) 64:165-8. doi: 10.1159/000514384

6. Menage L, Yodmeeklin A, Khamrin P, Kumthip K, Maneekarn N. Prevalence of human cosavirus and saffold virus with an emergence of saffold virus genotype 6 in patients hospitalized with acute gastroenteritis in Chiang Mai, Thailand, 2014-2016. Infect Genet Evol. (2017) 53:16. doi: 10.1016/j.meegid.2017.05.005

7. Ayouni S, Estienney M, Hammami S, Neji Guediche M, Pothier P, Aouni M, et al. Cosavirus, salivirus and bufavirus in diarrheal Tunisian infants. PLoS ONE. (2016) 11:e0162255. doi: 10.1371/journal.pone.01 62255

8. Cotmore SF, Agbandje-McKenna M, Canuti M, Chiorini JA, Eis-Hubinger AM, Hughes J, et al. ICTV virus taxonomy profile: parvoviridae. J Gen Virol. (2019) 100:367-8. doi: 10.1099/jgv.0.001212

9. Väisänen E, Kuisma I, Phan TG, Delwart E, Lappalainen M, Tarkka E, et al. Bufavirus in feces of patients with gastroenteritis, Finland. Emerg Infect Dis. (2014) 20:1077-9. doi: 10.3201/eid2006.131674

10. Christensen A, Kesti O, Elenius V, Eskola AL, Døllner H, Altunbulakli C, et al. Human bocaviruses and paediatric infections. Lancet Child AdolescHealth. (2019) 3:418-26. doi: 10.1016/S2352-4642(19)30057-4

11. Väisänen E, Paloniemi M, Kuisma I, Lithovius V, Kumar A, Franssila R, et al. Epidemiology of two human protoparvoviruses, bufavirus and tusavirus. Sci Rep. (2016) 6:39267. doi: 10.1038/srep39267

12. Zell R, Delwart E, Gorbalenya AE, Hovi T, King AMQ, Knowles NJ, et al. ICTV virus taxonomy profile: picornaviridae. J Gen Virol. (2017) 98:24212. doi: 10.1099/jgv.0.000911

13. Zell R. Picornaviridae-the ever-growing virus family. Arch Virol. (2018) 163:299-317. doi: 10.1007/s00705-017-3614-8

14. Tan SZK, Tan MZY, Prabakaran M. Saffold virus, an emerging human cardiovirus. Rev Med Virol. (2017) 27:e1908. doi: 10.1002/rmv.1908

\section{DATA AVAILABILITY STATEMENT}

The original contributions presented in the study are included in the article/supplementary materials, further inquiries can be directed to the corresponding author/s.

\section{AUTHOR CONTRIBUTIONS}

$\mathrm{MR}$ and $\mathrm{AK}$ designed the study and collaborated in the manuscript writing. MR and MZ collaborated in the studies search, data extraction, and double checking. MZ helped in revision. All authors commented on the drafts of the manuscript and approved the final version of the article.

15. Himeda T, Ohara Y. Saffold virus, a novel human cardiovirus with unknown pathogenicity. J Virol. (2012) 86:1292-6. doi: 10.1128/JVI.06087-11

16. Huang D-D, Wang W, Lu Q-B, Zhao J, Guo C-T, Wang H-Y, et al. Identification of bufavirus- 1 and bufavirus- 3 in feces of patients with acute diarrhea, China. Sci Rep. (2015) 5:1-4. doi: 10.1038/srep13272

17. Rezig D, Farhat EB, Touzi H, Meddeb Z, Salah AB, Triki H. Prevalence of human cosaviruses in Tunisia, North Africa. J Med Virol. (2015) 87:9403. doi: 10.1002/jmv.24076

18. Altay Koçak A, Öcal M, Polat M, Kanik Yüksek S, Aktaş Tapisiz A, Tezer H, et al. [Multicenter investigation of bufavirus in the etiology of viral central nervous system infections of adults and children]. Mikrobiyol Bul. (2017) 51:191-4. doi: 10.5578/mb.54035

19. Naeem A, Hosomi T, Nishimura Y, Alam MM, Oka T, Zaidi SSZ, et al. Genetic diversity of circulating Saffold viruses in Pakistan and Afghanistan. J Gen Virol. (2014) 95:1945-57. doi: 10.1099/vir.0.066498-0

20. Moher D, Liberati A, Tetzlaff J, Altman DG, Group P. Preferred reporting items for systematic reviews and meta-analyses: the PRISMA statement. PLoS Med. (2009) 6:e1000097. doi: 10.1371/journal.pmed.1000097

21. Phan TG, Vo NP, Bonkoungou IJ, Kapoor A, Barro N, O’Ryan M, et al. Acute diarrhea in West African children: diverse enteric viruses and a novel parvovirus genus. J Virol. (2012) 86:11024-30. doi: 10.1128/JVI.01427-12

22. Smits SL, Schapendonk CM, van Beek J, Vennema H, Schürch AC, Schipper D, et al. New viruses in idiopathic human diarrhea cases, the Netherlands. Emerg Infect Dis. (2014) 20:1218. doi: 10.3201/eid2007.140190

23. Yahiro T, Wangchuk S, Tshering K, Bandhari P, Zangmo S, Dorji T, et al. Novel human bufavirus genotype 3 in children with severe diarrhea, Bhutan. Emerg Infect Dis. (2014) 20:1037. doi: 10.3201/eid2006.131430

24. Altay A, Yahiro T, Bozdayi G, Matsumoto T, Sahin F, Ozkan S, et al. Bufavirus genotype 3 in Turkish children with severe diarrhoea. Clin Microbiol Infect. (2015) 21:965.e1-4. doi: 10.1016/j.cmi.2015.06.006

25. Chieochansin T, Vutithanachot V, Theamboonlers A, Poovorawan Y. Bufavirus in fecal specimens of patients with and without diarrhea in Thailand. Arch Virol. (2015) 160:1781-4. doi: 10.1007/s00705-015-2441-z

26. Mohammad HA, Madi NM, Al-Nakib W. Analysis of viral diversity in stool samples from infants and children with acute gastroenteritis in Kuwait using Metagenomics approach. Virol J. (2020) 17:10. doi: 10.1186/s12985-020-1287-5

27. Mohanraj U, Jokinen M, Thapa RR, Paloniemi M, Vesikari T, Lappalainen $\mathrm{M}$, et al. Human Protoparvovirus DNA and IgG in Children and Adults with and without Respiratory or Gastrointestinal Infections. Viruses. (2021) 13:483. doi: 10.3390/v13030483

28. Ren L, Gonzalez R, Xiao Y, Xu X, Chen L, Vernet G, et al. Saffold cardiovirus in children with acute gastroenteritis, Beijing, China. Emerg Infect Dis. (2009) 15:1509. doi: 10.3201/eid1509.081531

29. Khamrin P, Chaimongkol N, Nantachit N, Okitsu S, Ushijima H, Maneekarn N. Saffold cardioviruses in children with diarrhea, Thailand. Emerg Infect Dis. (2011) 17:1150. doi: 10.3201/eid1706.101983 
30. Dai X, Yuan C, Yu Y, Zhao W, Yang Z. Molecular detection of Saffold virus in children in Shanghai, China. J Clin Virol. (2011) 50:1867. doi: 10.1016/j.jcv.2010.11.004

31. Zhang X-A, Lu Q-B, Wo Y, Zhao J, Huang D-D, Guo C-T, et al. Prevalence and genetic characteristics of Saffold cardiovirus in China from 2009 to 2012. Sci Rep. (2015) 5:1-7. doi: 10.1038/srep07704

32. Khamrin P, Thongprachum A, Kikuta H, Yamamoto A, Nishimura S, Sugita K, et al. Three clusters of Saffold viruses circulating in children with diarrhea in Japan. Infect Genet Evol. (2013) 13:339-43. doi: 10.1016/j.meegid.2012.11.004

33. Nielsen ACY, Gyhrs ML, Nielsen LP, Pedersen C, Böttiger Gastroenteritis B, and the novel picornaviruses aichi virus, cosavirus, saffold virus, and salivirus in young children. J Clin Virol. (2013) 57:239-42. doi: 10.1016/j.jcv.2013.03.015

34. Yodmeeklin A, Khamrin P, Chuchaona W, Saikruang W, Malasao R, Chaimongkol N, et al. Saffold viruses in pediatric patients with diarrhea in Thailand. J Med Virol. (2015) 87:702-7. doi: 10.1002/jmv.24114

35. Thongprachum A, Khamrin P, Pham NTK, Takanashi S, Okitsu S, Shimizu $\mathrm{H}$, et al. Multiplex RT-PCR for rapid detection of viruses commonly causing diarrhea in pediatric patients. J Med Virol. (2017) 89:81824. doi: $10.1002 /$ jmv. 24711

36. Kumthip K, Khamrin P, Ushijima H, Maneekarn N. Multiple enterovirus genotypes circulating in children hospitalized with acute gastroenteritis in Thailand. Infect Genet Evol. (2017) 55:324-31. doi: 10.1016/j.meegid.2017.10.002

37. Li L-1, Liu N, Yu J-m, Ao Y-y, Li S, Stine OC, et al. Analysis of Aichi virus and Saffold virus association with pediatric acute gastroenteritis. J Clin Virol. (2017) 87:37-42. doi: 10.1016/j.jcv.2016.12.003

38. Daprà V, Montanari P, Rassu M, Calvi C, Galliano I, Bergallo M. Prevalence of human cosavirus and saffold virus in young children with gastroenteritis, Northern Italy. Minerva Pediatr. (2018). doi: 10.23736/s0026-4946.18.05219-2

39. Malasao R, Khamrin P, Kumthip K, Ushijima H, Maneekarn N. Molecular epidemiology and genetic diversity of human parechoviruses in children hospitalized with acute diarrhea in Thailand during 2011-2016. Arch Virol. (2019) 164:1743-52. doi: 10.1007/s00705-019-04249-2

40. Kim GR, Kim SH, Jeon GW, Shin JH. Prevalence of eleven infectious viruses causing diarrhea in Korea. Jpn J Infect Dis. (2020) 73:42730. doi: 10.7883/yoken.JJID.2020.069

41. Vandesande H, Edman K, Rondahl E, Falkeborn T, Serrander L, Lindberg AM. Saffold virus infection in elderly people with acute gastroenteritis in Sweden. $J$ Med Virol. (2021) 93:3980-4. doi: 10.1002/jmv.26452

42. Yaghobi TS, Bahrami H, Harzandi N, Asadi A, Shareghi M, Firouzjani $\mathrm{MH}$, et al. First molecular detection of saffold virus in children with acute gastroenteritis in iran. Novelty in Biomedicine. 9:11-6.

43. Taghinejad M, Ghaderi M, Mousavi-Nasab SD. First molecular detection of aichivirus in pediatric patients with acute gastroenteritis in Iran. Novelty Biomed. (2020) 8:20-5. doi: 10.22037/nbm.v7i4.26729

44. Stöcker A, Souza BFdCD, Ribeiro TCM, Netto EM, Araujo LO, Corrêa JI, et al. Cosavirus infection in persons with and without gastroenteritis, Brazil. Emerg Infect Dis. (2012) 18:656. doi: 10.3201/eid1804.111415

45. Vizzi E, Fernández R, Angulo LA, Blanco R, Pérez C. Human cosavirus infection in HIV subjects with diarrhoea: persistent detection associated with fatal outcome. J Clin Virol. (2021) 139:104825. doi: 10.1016/j.jcv.2021.104825

46. Yu J-M, Ao Y-Y, Li L-L, Duan Z-J. Identification of a novel cosavirus species in faeces of children and its relationship with acute gastroenteritis in China. Clin Microbiol Infect. (2017) 23:550-4. doi: 10.1016/j.cmi.2017.02.018

47. Khamrin P, Chaimongkol N, Malasao R, Suantai B, Saikhruang W, Kongsricharoern T, et al. Detection and molecular characterization of cosavirus in adults with diarrhea, Thailand. Virus Genes. (2012) 44:2446. doi: $10.1007 / \mathrm{s} 11262-011-0700-y$

48. Khamrin P, Maneekarn N. Detection and genetic characterization of cosavirus in a pediatric patient with diarrhea. Arch Virol. (2014) 159:24859. doi: 10.1007/s00705-014-2091-6

49. Okitsu S, Khamrin P, Thongprachum A, Nishimura S, Kalesaran AF, Takanashi S, et al. Detection and molecular characterization of human cosavirus in a pediatric patient with acute gastroenteritis, Japan. Infect Genet Evol. (2014) 28:125-9. doi: 10.1016/j.meegid.2014. 09.019
50. Rovida F, Campanini G, Piralla A, Adzasehoun KMG, Sarasini A, Baldanti F. Molecular detection of gastrointestinal viral infections in hospitalized patients. Diagnostic microbiology and infectious disease. (2013) 77:231-5. doi: 10.1016/j.diagmicrobio.2013. 07.020

51. Kochjan P, Khamrin P, Kumthip K, Maneekarn N. Detection and Characterization of Human Bocavirus in Pediatric Patients with Acute Gastroenteritis in Chiang Mai, Thailand.

52. Razizadeh MH, Khatami A, Zarei M. Global molecular prevalence and genotype distribution of Sapovirus in children with gastrointestinal complications: a systematic review and meta-analysis. Rev Med Virol. (2021) e2302. doi: 10.1002/rmv. 2302

53. Kesheh MM, Khatami A, Saadati H, Jabbari M, Razizadeh $\mathrm{MH}$, Fatemipour $\mathrm{M}$, et al. Salivirus infection: systematic review and meta-analysis of association with gastrointestinal symptoms in children. Rev Med Virol. (2021) e2238. doi: 10.1002/ rmv.2238

54. Taghipour A, Bahadory S, Badri M, Yadegar A, Mirsamadi ES, Mirjalali $\mathrm{H}$, et al. A systematic review and meta-analysis on the co-infection of Helicobacter pylori with intestinal parasites: public health issue or neglected correlation? Int $J$ Environ Health Res. (2020) 1-11. doi: 10.1080/09603123.2020.17 98890

55. Taghipour A, Olfatifar M, Foroutan M, Bahadory S, Malih N, Norouzi M. Global prevalence of Cryptosporidium infection in rodents: a systematic review and meta-analysis. Prev Vet Medi. (2020) 105119. doi: 10.1016/j.prevetmed.2020. 105119

56. Khatami A, Bahadory S, Ghorbani S, Saadati H, Zarei M, Soleimani A, et al. Two rivals or colleagues in the liver? Hepatit B virus and Schistosoma mansoni co-infections: a systematic review and metaanalysis. Microbial Pathogen. (2021) 104828. doi: 10.1016/j.micpath.2021.10 4828

57. López GR, Martinez LM, Freyre L, Freire MC, Vladimirsky S, Rabossi A, et al. Persistent detection of Cosavirus and Saffold cardiovirus in Riachuelo River, Argentina. Food Environ Virol. (2021) 13:64-73. doi: 10.1007/s12560-020-09 451-z

58. Guerrero-Latorre L, Romero B, Bonifaz E, Timoneda N, Rusiñol M, Girones R, et al. Quito's virome: metagenomic analysis of viral diversity in urban streams of Ecuador's capital city. Sci Total Environ. (2018) 645:1334-43. doi: 10.1016/j.scitotenv.2018. 07.213

59. Nantachit N, Khamrin P, Kumthip K, Malasao R, Maneekarn N. Molecular surveillance and genetic analyses of bufavirus in environmental water in Thailand. Infect Genet Evol. (2019) 75:104013. doi: 10.1016/j.meegid.2019. 104013

60. Thongprachum A, Fujimoto T, Takanashi S, Saito H, Okitsu S, Shimizu $\mathrm{H}$, et al. Detection of nineteen enteric viruses in raw sewage in Japan. Infect Genet Evol. (2018) 63:17-23. doi: 10.1016/j.meegid.2018. 05.006

61. Bonanno Ferraro G, Mancini P, Veneri C, Iaconelli M, Suffredini E, Brandtner D, et al. Evidence of Saffold virus circulation in Italy provided through environmental surveillance. Lett Appl Microbiol. (2020) 70:1028. doi: 10.1111/lam.13249

62. Aminipour M, Ghaderi M, Harzandi N. First occurrence of Saffold virus in sewage and river water samples in Karaj, Iran. Food Environ Virol. (2020) 12:75-80. doi: 10.1007/s12560-019-09 $415-\mathrm{y}$

63. Blinkova O, Kapoor A, Victoria J, Jones M, Wolfe N, Naeem A, et al. cardioviruses are genetically diverse and cause common enteric infections in South Asian children. J Virol. (2009) 83:4631-41. doi: 10.1128/JVI. 02085-08

64. Bányai K, Estes MK, Martella V, Parashar UD. Viral gastroenteritis. Lancet. (2018) 392:175-86. doi: 10.1016/S0140-6736(18)31128-0

65. Nguyen GT, Phan K, Teng I, Pu J, Watanabe T. A systematic review and meta-analysis of the prevalence of norovirus in cases of gastroenteritis 
in developing countries. Medicine. (2017) 96:e8139. doi: 10.1097/MD. 0000000000008139

66. Ghaderi M. First molecular detection of Saffold virus in children with acute gastroenteritis in Iran. Novelty Biomed. (2021) 9:11-6. doi: $10.22037 / \mathrm{nbm} . v i .31662$

Conflict of Interest: The authors declare that the research was conducted in the absence of any commercial or financial relationships that could be construed as a potential conflict of interest.

Publisher's Note: All claims expressed in this article are solely those of the authors and do not necessarily represent those of their affiliated organizations, or those of the publisher, the editors and the reviewers. Any product that may be evaluated in this article, or claim that may be made by its manufacturer, is not guaranteed or endorsed by the publisher.

Copyright (๑ 2022 Razizadeh, Khatami and Zarei. This is an open-access article distributed under the terms of the Creative Commons Attribution License (CC BY). The use, distribution or reproduction in other forums is permitted, provided the original author(s) and the copyright owner(s) are credited and that the original publication in this journal is cited, in accordance with accepted academic practice. No use, distribution or reproduction is permitted which does not comply with these terms. 